\title{
Signos distintivos territoriais e indicação geográfica: uma avaliação de experiências com a aplicação de instrumental metodológico ${ }^{1}$
}

\author{
Territorial signs and geographical indication: an evaluation of experiences with \\ the application of methodological instrumental
Signos territoriales e indicación geográfica: evaluación de experiencias con la aplicación de instrumental metodológico

\author{
Valdir Roque Dallabrida² \\ Kelly Samantha Baukart ${ }^{2}$ \\ Walison Guinzani
}

Recebido em 08/07/2019; revisado e aprovado em 31/10/2019; aceito em: 02/12/2019.

DOI: http://dx.doi.org/10.20435/inter.v21i1.2635

\begin{abstract}
Resumo: A avaliação de experiências de associativismo territorial, sob a forma de signos distintivos territoriais, como as de Indicação Geográfica, precisa centrar-se nas questões relacionadas à dinâmica territorial, às condições socioeconômicas, históricas, culturais e ambientais do território. Utilizando de forma experimental um instrumento de pesquisa, direcionado aos atores envolvidos na experiência, validou-se a metodologia e evidenciaram-se os aspectos positivos da experiência em estudo e os avanços necessários.
\end{abstract}

Palavras-chave: signos distintivos territoriais; indicação geográfica; associativismo territorial.

Abstract: The evaluation of experiences of territorial associativism, in the form of territorial distinctive signs, such as those of Geographical Indication, need to focus on issues related to territorial dynamics, socioeconomic, historical, cultural and environmental conditions. Using a research instrument aimed at the actors involved, the methodology was validated, and the positive aspects of the study experience and the necessary advances were evidenced.

Keywords: territorial distinctive signs; geographical indication; territorial association.

Resumen: La evaluación de experiencias de asociativismo territorial, en forma de signos distintivos territoriales, como los de la Indicación Geográfica, debe centrarse en cuestiones relacionadas con la dinámica territorial, las condiciones socioeconómicas, históricas, culturales y ambientales. Utilizando un instrumento de investigación dirigido a los actores involucrados, se validó la metodología y se evidenciaron los aspectos positivos de la experiencia de estudio y los avances necesarios.

Palabras clave: signos distintivos territoriales; indicacion geografica; asociativismo territorial.

\section{INTRODUÇÃO}

Algumas regiões possuem produtos ou serviços com especificidade territorial, os quais podem resultar em experiências de Indicação Geográfica (IG). Estas têm potencialidade de se constituírem em signos distintivos territoriais (DALLABRIDA, 2019a; 2019b; DALLABRIDA et al., 2019). O estudo do tema é recente, mas de suma importância.

As experiências em IG no Brasil são muito recentes, sendo que as primeiras são da década de 1990, no entanto a maior parte dos registros ocorreu nos últimos dez anos. Atualmente, são mais de sessenta experiências reconhecidas, porém é um número pouco significativo, se considerarmos que alguns países europeus de menor tamanho possuem centenas delas.

A partir da primeira década do Século XX, ampliou-se o número de investigações sobre as experiências de associativismo territorial - algumas delas com possibilidades de se habilitarem

\footnotetext{
${ }^{1} \mathrm{O}$ artigo apresenta resultados parciais do Projeto de Pesquisa Signos Distintivos Territoriais, Indicação Geográfica e Desenvolvimento Territorial, com financiamento do CNPq.

${ }^{2}$ Universidade do Contestado (UnC), Mafra, Santa Catarina, Brasil.
} 
à obtenção do instituto de IG. O que os estudos demonstraram é que muitas das IGs, apesar de já terem registro, têm sérios problemas de funcionamento. Com relação às que estão sendo planejadas para registro, o processo apresenta lacunas. Um dos desafios ainda não superados é o fato de que a preocupação central, quando do registro de uma IG, restringe-se, quase exclusivamente, ao atendimento das questões legais, atendo-se muito pouco às questões relacionadas à dinâmica territorial, ou seja, às condições socioeconômicas e culturais, relegando a um segundo plano a verificação de o saber fazer ser dominado territorialmente, de o produto ter realmente especificidades, de haver ou não reconhecimento local e externo, entre outros aspectos.

Por exemplo, o Estado de Santa Catarina, pela sua diversidade sociocultural e de paisagens naturais, apresenta diferentes produtos com especificidade territorial, conforme já demonstrado em estudo recente (SAKR; DALLABRIDA, 2015). No entanto, até o final de 2019, estavam com o registro de reconhecimento duas experiências de IG: a do Vale da Uva Goethe e da Banana da Região de Corupá. Várias outras experiências estão ou em estudo, ou em processo de solicitação de registro, como o exemplo do Queijo Serrano. Quanto às experiências de IG registradas e em estudo atualmente, percebe-se um diferencial em relação a vários outros estados: uma forte preocupação com a organização socioterritorial da área atingida pela IG. Isso demanda um processo de articulação institucional e governamental, o qual se tem observado, em especial, no órgão estadual de pesquisa e extensão rural (Empresa de Pesquisa Agropecuária e Extensão Rural de Santa Catarina - EPAGRI), juntamente das universidades regionais. Os principais destaques no processo de organização são a continuidade e a presença regional permanente, com técnicos e pesquisadores ${ }^{3}$.

Para o estudo da temática das Indicações Geográficas no Estado de Santa Catarina, vários projetos de pesquisa já foram desenvolvidos, um deles em fase de execução, intitulado Signos Distintivos Territoriais, Indicação Geográfica, Governança e Desenvolvimento Territorial: estudos sobre os desafios e perspectivas com base em experiências do Brasil, de países latino-americanos e europeus, estando focado numa temática complementar, que é o caso dos signos distintivos. Este texto é um primeiro resultado deste projeto de pesquisa, o qual contou com a participação de dois alunos de Iniciação Científica ${ }^{4}$.

Apesar dos estudos já realizados e outros em fase de execução, o tema precisa continuar sendo aprofundado. Justifica-se, em especial, pelo fato de os estudos já realizados apontarem poucos exemplos de sucesso e muitos desafios ainda não superados, no caso das experiências de IG já registradas. No caso das que estão em processo de registro, da mesma forma, percebem-se lacunas, para as quais novos estudos poderão apresentar indicativos de melhora dos processos.

No projeto de pesquisa do qual resultou este artigo, propôs-se ampliar a reflexão teórica sobre IG, incluindo a discussão sobre signos distintivos territoriais, além de avaliar a experiência já registrada ou em processo de registro. O estudo teve como objetivo central avaliar experiências de especificação de ativos territoriais, com potencialidade de se constituírem em signos distintivos

\footnotetext{
${ }^{3}$ A afirmação está sustentada em estudos realizados entre 2013 e 2015, relatados em livro - Dallabrida (2015) -, que está disponível para o livre acesso em: http://redeteg.org/livros/.

${ }^{4}$ O projeto "guarda-chuva", acima mencionado, conta com apoio financeiro do CNPq, enquanto os dois projetos de Iniciação Científica contaram com apoio financeiro do Fundo de Apoio à Pesquisa e do Artigo 170 (SE-Santa Catarina).
} 
territoriais, como as de Indicação Geográfica. Trata-se da avaliação de duas experiências de IG, uma já registrada e outra em fase de registro. O estudo serviu para testagem de uma proposta metodológica explicitada em Dallabrida (2019a; 2019b), com o fim de avaliar as condições da dinâmica territorial engendrada no processo de organização, considerando as experiências de IG como exemplo de signos distintivos territoriais.

Assim, o artigo, além desta introdução, está estruturado em mais quatro partes: uma rápida discussão conceitual, a explicitação do percurso metodológico, a apresentação dos resultados da aplicação do instrumento de pesquisa e as considerações finais.

\section{UM REFERENCIAL TEÓRICO}

\subsection{A instância territorial como lócus dos signos distintivos territoriais}

A referência à dinâmica territorial do desenvolvimento justifica-se pelo fato de que se entende que o desenvolvimento ocorre localizadamente, no território, na região, no município, envolvendo atores públicos e privados, em processos de debate e proposição do futuro (DALLABRIDA, 2016a; 2007). É nesta instância espacial que ocorrem processos socioeconômico-culturais que resultam, por exemplo, no reconhecimento de produtos ou serviços com especificidade territorial (CHAMPREDONDE, 2012), na forma de signos distintivos territoriais (DALLABRIDA, 2019a), alguns dos quais atendem às exigências para registro como Indicação Geográfica (IG) (DALLABRIDA, 2013; 2014; 2015; 2016a; 2016b). Tais estratégias apresentam potencialidades de contribuição no desenvolvimento territorial (DALLABRIDA, 2016a; 2017) das áreas abrangidas pelas experiências.

Sustentam Dallabrida, Covas e Covas (2017) que vivemos num período de transição paradigmática da sociedade dos objetos para a (i)conomia, o que representa a transição para a sociedade dos ícones, ou signos. Assim, um determinado signo pode fazer referência, por exemplo, a um produto ou serviço cuja notoriedade e especificidade remetem a um determinado território, numa relação constante entre produto e território, em que tanto o produto quanto o território se beneficiam dessa notoriedade.

Com isso, propugna-se a revalorização dos territórios (PECQUEUR, 2009; DALLABRIDA, 2019a), mesmo admitindo a possibilidade de transição dos atuais territórios-zona para territórios-rede, combinação articulada de redes, na forma de malhas (HAESBAERT, 2011), em geral desterritorializantes, mas que, também, podem ser a base de um novo processo de territorialização (SAQUET, 2015).

Esse processo cognitivo e criativo de construção do território-rede trata do que se convencionou denominar smartificação do território. A smartificação do território inscreve-se no movimento geral de digitalização dos objetos (naturais e culturais), gerando potenciais de estimular tanto inovações materiais (ex. impressoras 3D), compreendidas como inteligência artificial, como inovações sociais ou inteligência social, favorecendo novas produções de proximidade e/ou agroecológicas, por exemplo, ou mesmo processos de valorização e reconhecimento de produtos com especificidade territorial (COVAS, 2018).

O signo, para Bruch (2011), representa um objeto (material ou imaterial), embora ele não seja nem abarque o próprio objeto, tendo a função de distingui-lo de outros objetos, semelhantes ou afins. A Constituição Brasileira faz referência aos signos no título que se refere aos direitos e às garantias fundamentais, mais especificamente, no capítulo em que trata dos direitos e deveres 
individuais e coletivos. É decorrente dessa previsão legal que, no caso do Brasil, há uma legislação específica sobre signos distintivos, como o caso da IG e das Marcas Coletivas.

\subsection{As experiências de Indicação Geográfica como signos distintivos territoriais}

Sobre as IGs, várias publicações já trataram do tema, por exemplo, Dallabrida (2014; 2015; 2016a; 2016b), Mascarenhas e Wilkinson (2014), Niederle (2013) e Champredonde (2012), o que nos permite optar por não aprofundar o tema neste texto.

Atualmente, proliferam diferentes sistemas de garantia da qualidade, competindo entre si, situação que tem contribuído até para a trivialização ou "banalização dos signos" (GARRIDO; RAMOS, 2013). Outro desafio é a percepção sobre o pouco conhecimento que existe por parte do consumidor acerca do que certifica cada tipo de selo que representa um signo (PAVÓN; GÓMEZ MUNHÓZ, 2009).

Decorrente dessas constatações, alguns autores têm defendido que a implantação de selos que certificam a qualidade e/ou origem de produtos por si só não é garantia de êxito, mesmo que se cumpram os requisitos exigidos pela legislação vigente sobre o tema, como o caso das experiências de Indicação Geográfica (CHAMPREDONDE; CASIOROVSKI, 2016; VANDECANDELAERE et al., 2011), reforçando a necessidade de se considerarem com maior profundidade os processos que ocorrem na dinâmica territorial.

Apesar da extensa literatura sobre o tema, permanece um desafio: quais parâmetros e critérios são referenciais para prospecção ou avaliação de experiências de signos distintivos territoriais? Essa questão é da maior importância, exigindo-se elaborar instrumentos de pesquisa, os quais possam ser utilizados na avaliação de experiências, sejam as que já têm registro ou mesmo para avaliar a dinâmica territorial empreendida no processo socioeconômico-cultural voltado ao registro, buscando sugestões metodológicas já testadas internacionalmente para tal, como os textos aqui mencionados (DALLABRIDA, 2019a; 2019b).

\subsection{Parâmetros e critérios para prospecção ou avaliação de experiências de signos distintivos territoriais}

São raras as publicações que têm se preocupado com a elaboração de parâmetros e critérios para a prospecção e/ou avaliação de experiências que se apresentem na forma de signos distintivos territoriais. Uma delas é de Vandecandelaere et al. (2011), que, na forma de um guia, apresenta indicativos para acompanhamento de experiências de IG.

Outros autores avançam, fazendo referência às IGs como signos distintivos. Por exemplo, Martínez-Villalba (2014) traz à tona o debate sobre os princípios gerais aplicáveis aos signos distintivos, mencionando onze deles: da veracidade, da não confusão, da unidade, da boa-fé, da legítima defesa, da temporalidade, da territorialidade, da especialidade, da livre opção, do mínimo uso e da registrabilidade.

Já Aranda Camacho (2015) propõe um modelo de decisão para orientar a seleção de selos de origem, que contemple as aptidões que existem nos territórios por parte dos atores, capazes de gerar as dinâmicas internas necessárias "[...] que conduzam a construir a arquitetura institucional necessária para garantir o êxito da implementação do distintivo" (ARANDA CAMACHO, 2015, p. 133). O autor, na estrutura de modelo proposto por ele, centra-se em três dimensões - vínculo territorial da produção, reconhecimento do produto e dinâmica territorial -, sendo que em cada uma delas destaca critérios e subcritérios. 
Portanto a contribuição desses dois autores é fundamental para se estruturar um instrumento de pesquisa para ser aplicado e atender aos objetivos da investigação da qual resultou o presente texto.

\section{O PERCURSO METODOLÓGICO}

Em Dallabrida (2019a; 2019b) é apresentada uma proposta metodológica para a prospecção e/ou avaliação de experiências de signos distintivos territoriais. A proposta resultou num instrumento de pesquisa, principalmente, com base nas contribuições teóricas de dois autores: os princípios aplicáveis aos signos distintivos territoriais sugeridos por Martínez-Villalba (2014) e as dimensões e os critérios sugeridos por Aranda Camacho (2015). Resultou numa proposta metodológica com questões objetivas, na forma de checklist, com dimensões e parâmetros para a prospecção e/ou avaliação de experiências de associativismo territorial, como as de IG, que possam ser consideradas no patamar de signos distintivos territoriais. Essa proposta tem por finalidade investigar as dimensões e os parâmetros para a prospecção e/ou avaliação de experiências de associativismo territorial, com o caso das que se constituem em signos distintivos territoriais.

O instrumento de pesquisa foi elaborado para utilização em pesquisas de campo, utilizando uma escala Likert de significância. Assim, a proposta metodológica sugerida é estruturada com quatro dimensões: (i) formas de reconhecimento de signos distintivos territoriais; (ii) vínculo territorial da produção; (iii) reconhecimento da notoriedade ou reputação do produto específico; (iv) avaliação da dinâmica territorial do setor produtivo envolvido na experiência de IG. A proposta é explicitada no Quadro 1, conforme abaixo. 


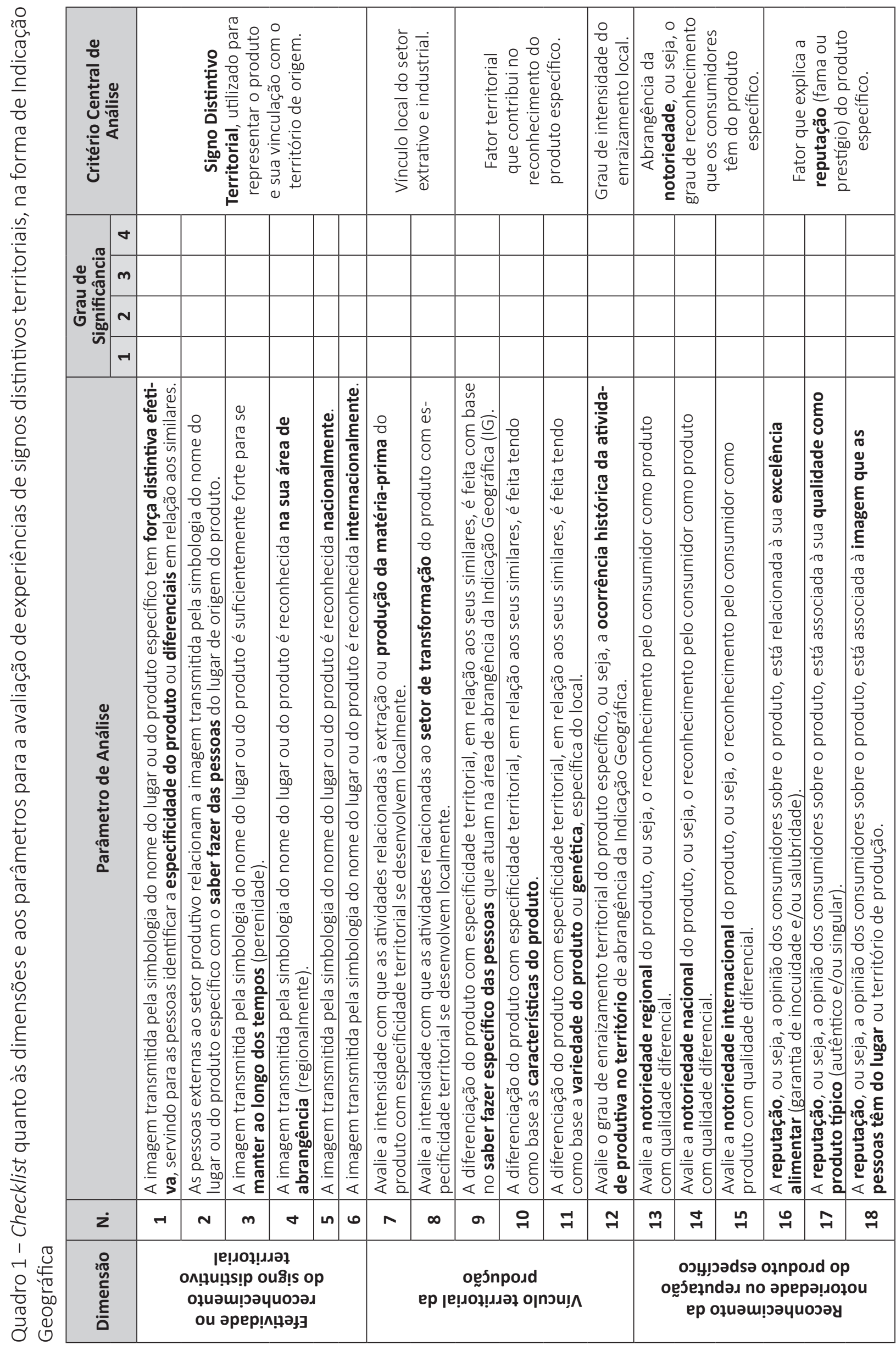




\begin{tabular}{|c|c|c|c|c|c|c|c|c|c|c|}
\hline \multicolumn{2}{|c|}{ 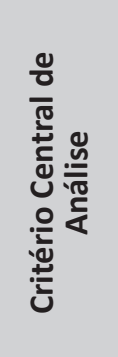 } & \multicolumn{3}{|c|}{ 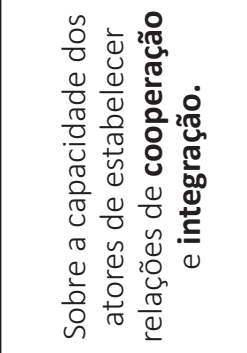 } & \multirow[t]{2}{*}{ 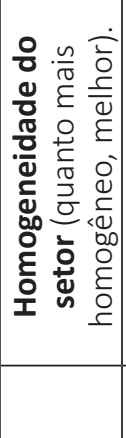 } & \multicolumn{4}{|c|}{ 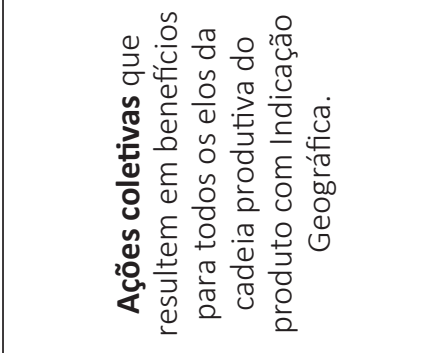 } & \\
\hline \multirow{4}{*}{ 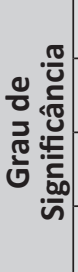 } & $\nabla$ & & & & & & & & & \\
\hline & $m$ & & & & & & & & & \\
\hline & $\mathbf{N}$ & & & & & & & & & \\
\hline & $r$ & & & & & & & & & \\
\hline \multicolumn{2}{|c|}{ 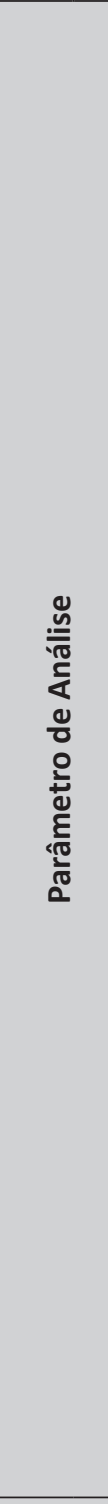 } & 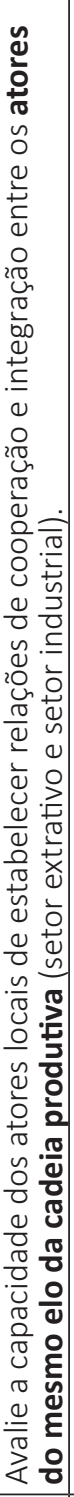 & 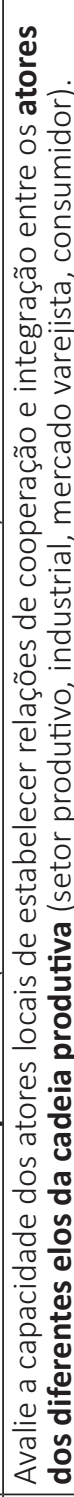 & 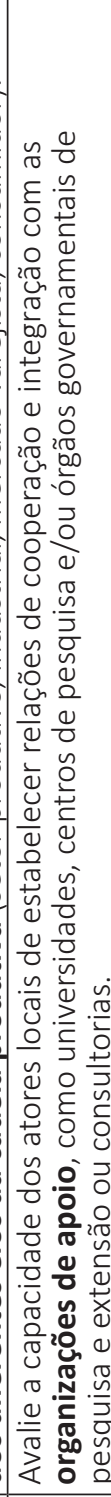 & 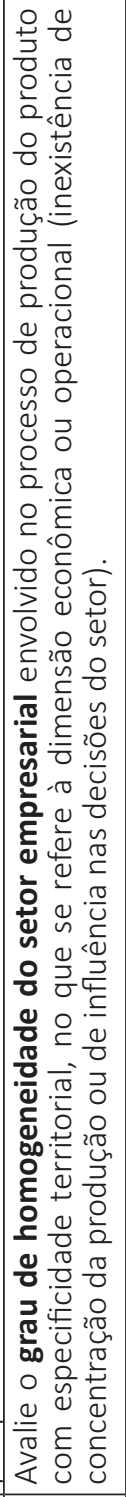 & 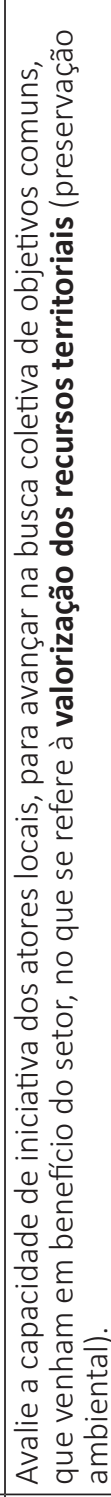 & 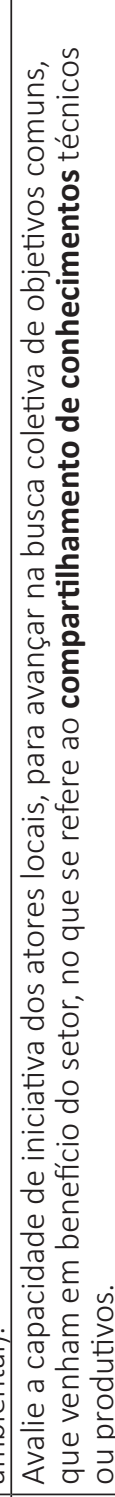 & 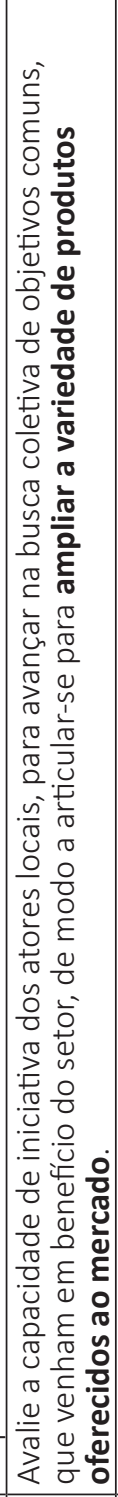 & 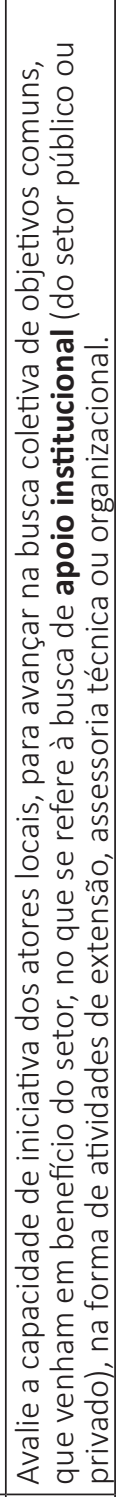 & 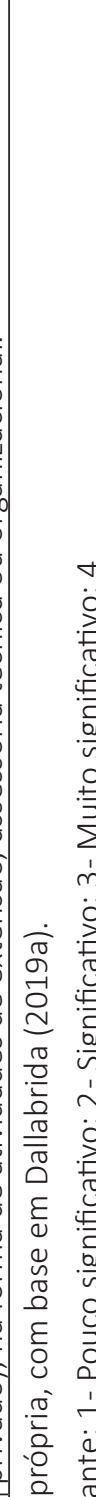 \\
\hline$z$ & & $\stackrel{9}{-}$ & 오 & $\vec{N}$ & $\approx$ & $\ddot{N}$ & $\underset{N}{ }$ & $\stackrel{n}{N}$ & $\stackrel{N}{N}$ & \\
\hline 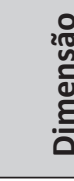 & & \multicolumn{8}{|c|}{ 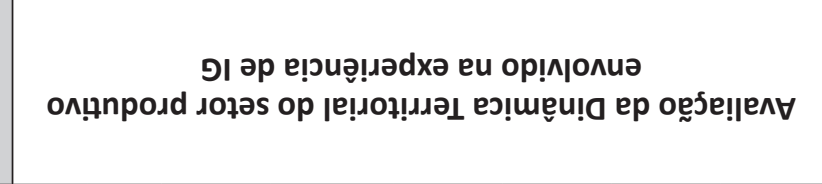 } & 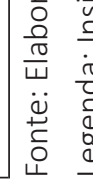 \\
\hline
\end{tabular}


No estudo do qual resultou este texto, o instrumento metodológico apresentado no Quadro 1 foi aplicado com lideranças envolvidas no processo de organização de duas experiências de IG brasileiras $^{5}$. Utilizou-se uma amostra, tomando como critério a lista de presenças nas reuniões ocorridas no processo de organização. Foi enviado o instrumento de pesquisa por e-mail a todos os que constavam da lista. Para estimular a participação na resposta ao instrumento de pesquisa, foram feitas visitas de motivação junto aos organizadores das reuniões, além de contatos com instituições envolvidas no processo de organização das IGs. O propósito foi de que cada respondente manifestasse sua percepção, valorando as questões pelo grau de significância, desde um grau de insignificância total até muito significativo.

Das duas experiências, em uma delas houve o retorno de um número muito pequeno de questionários respondidos. Em função deste motivo, a avaliação foi de que não seriam representativos da realidade estudada. Por isso, estes questionários foram desconsiderados e, portanto, a análise foi feita somente a partir de uma das duas experiências.

No caso da experiência utilizada para a análise, foram expedidos 52 questionários, tendo retornado 27, portanto, sendo considerada uma amostra representativa. Envolveu lideranças, empresários, agricultores e técnicos extensionistas. No questionário, para balizar a resposta das questões de número um a seis, foi apresentada a imagem do signo distintivo da experiência analisada.

\section{ANÁLISE DE RESULTADOS}

As respostas dadas no instrumento de pesquisa aplicado foram sistematizadas em gráficos, conforme segue, a fim de facilitar a leitura e interpretação das informações. Os gráficos foram distribuídos de forma a representar cada um dos critérios centrais de análise. Assim, na sequência do texto, faz-se a apresentação dos dados e sua análise.

\footnotetext{
${ }^{5}$ Optou-se por manter o sigilo quanto ao nome das experiências nas quais o instrumento de pesquisa foi aplicado.
} 
Figura 1 - Signo Distintivo Territorial utilizado para representar o produto e sua vinculação com o território

1- A imagem transmitida pela simbologia do nome do lugar ou do produto específico retrata com veracidade a realidade, ou seja, tem força distintiva efetiva, servindo para as pessoas identificar a especificidade do produto erva-mate ou os diferenciais em relação aos similares.

2- As pessoas externas ao setor produtivo vinculam a imagem transmitida pela simbologia do nome do lugar ou do produto específico com o saber fazer das pessoas do lugar de origem do produto.

5- A imagem transmitida pela simbologia do nome do lugar ou do produto é reconhecida nacionalmente.

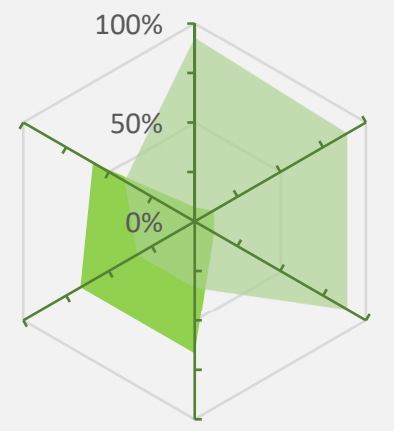

3- A imagem transmitida pela simbologia do nome do lugar ou do produto é suficientemente forte para se manter ao longo dos tempos (perenidade).

4- A imagem transmitida pela simbologia do nome do lugar ou do produto é reconhecida na sua área de abrangência (regionalmente).

6- A imagem transmitida pela simbologia do nome do lugar ou do produto é reconhecida internacionalmente.

Fonte: Elaborada pelos autores a partir dos dados da pesquisa (2019).

Na Figura 1, é avaliada a efetividade no reconhecimento do signo distintivo territorial. A análise permite observar que fica evidente que a imagem transmitida pelo signo distintivo da experiência em análise expressa com clareza a realidade representada, ou seja, o contexto socioeconômico, a história e as características específicas do lugar, pois 89\% dos respondentes consideram muito significativa a força distintiva da imagem. Já quanto à vinculação da imagem ao saber fazer das pessoas envolvidas na experiência, os respondentes consideram que isso ainda ocorre de forma parcial (59\%, somente, avaliaram como significativo). Em relação à perenidade do signo distintivo para representar a realidade em estudo, a avaliação foi positiva, pois também $89 \%$ responderam ser muito significativo.

Ainda na Figura 1, pelas respostas, verifica-se que a imagem transmitida pela simbologia do lugar e produto específico da experiência de IG em estudo, através de seu signo distintivo, só tem reconhecimento muito significativo regionalmente (89\%). Tanto nacionalmente como internacionalmente, a avaliação dos respondentes não é significativa, pois apenas 59\% apontaram como significativa. Isso indica a necessidade de ações de divulgação, tanto nacionalmente como internacionalmente, de parte dos atores integrantes da experiência em análise. 
Figura 2 - Vínculo local do setor produtivo e industrial e enraizamento territorial da produção

12- Grau de intensidade do

7- Intensidade com que as atividades relacionadas ao setor produtivo (produtor), do produto com

especificidade territorial, se desenvolvem localmente.

enraizamento local, ou seja, a

ocorrência histórica da atividade

produtiva no território de origem.

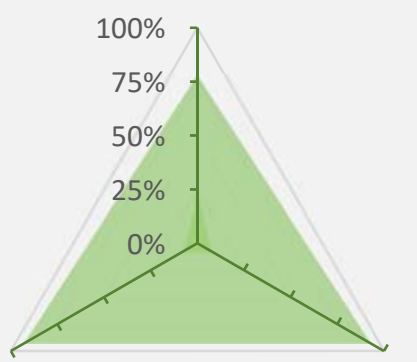

8- Intensidade com que as atividades

relacionadas ao setor de

transformação (indústria e comércio),

do produto com especificidade

Pouco Significativo $\quad$ Muito Significativo

territorial, se desenvolvem localmente.

Fonte: Elaborada pelos autores a partir dos dados da pesquisa (2019).

Já na Figura 2 são avaliadas duas variáveis: o vínculo local do setor extrativo (produtor rural) e industrial e o grau de enraizamento territorial da experiência de IG em análise. Quanto ao vínculo local do setor produtivo, este é significativo (corresponde a $78 \%$ das respostas), no entanto é ressaltada a presença local do setor de transformação, bem como o grau de enraizamento territorial da atividade produtiva, ambos com 93\% das respostas. Todos eles são fatores competitivos importantes para o setor, que facilitam a solidificação da IG.

A Figura 3 refere-se à menção dos fatores territoriais pelos quais o produto específico é reconhecido. O fator saber fazer específico das pessoas é considerado medianamente significativo, com $63 \%$ das respostas. As características específicas do produto de IG merecem o maior destaque, com $85 \%$ das respostas. Ou seja, as características específicas do produto são consideradas o fator de destaque, segundo a opinião dos respondentes. Já o reconhecimento do produto pelas suas diferenças com base na variedade do produto foi menos considerado (59\%), apesar de medianamente significativo. 
Figura 3 - Fator territorial que contribui no reconhecimento do produto específico

9- A diferenciação do produto com especificidade territorial, em relação aos seus similares, é feita com base no saber fazer específico das pessoas que atuam na área de abrangência da Indicação Geográfica (IG).

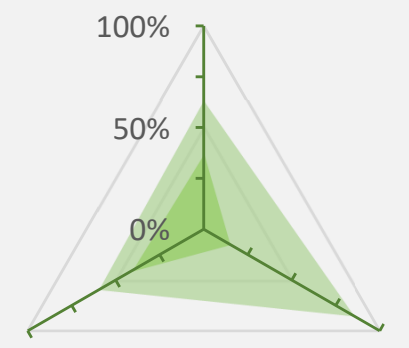

11- A diferenciação do produto com especificidade territorial, em relação aos seus similares, é feita tendo como base a variedade do produto ou genética específica do local.
10- A diferenciação do produto com especificidade territorial, em relação aos seus similares, é feita tendo como base as características do produto.

- Pouco Significativo $\square$ Muito Significativo

Fonte: Elaborada pelos autores a partir dos dados da pesquisa (2019).

Figura 4 - Abrangência da notoriedade

13- Grau de notoriedade regional do produto, ou seja, o reconhecimento pelo consumidor como produto com qualidade diferencial.

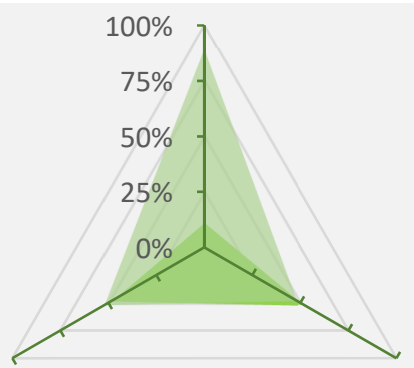

15- Grau de notoriedade internacional do produto, ou seja, o reconhecimento pelo consumidor como produto com qualidade diferencial.
14- Grau de notoriedade nacional do produto, ou seja, o reconhecimento pelo consumidor como produto com qualidade diferencial.

Fonte: Elaborada pelos autores a partir dos dados da pesquisa (2019).- OK

A Figura 4 refere-se à abrangência da notoriedade do produto de IG, ou seja, o grau de reconhecimento que os clientes têm do produto específico. Pelos dados da pesquisa, a notoriedade do produto é muito significativa apenas no âmbito regional (89\%). Já nacional e internacionalmente, o produto tem baixo reconhecimento, em torno de $50 \%$. Isso implica que os articuladores da experiência de IG em análise precisam divulgar muito mais o produto, tanto nacional como internacionalmente. 
Figura 5 - Fator que explica a reputação (fama ou prestígio) do produto específico

16- A reputação, ou seja, a opinião dos consumidores
sobre o produto, está relacionada à sua excelência
alimentar (garantia de inocuidade e/ou salubridade).

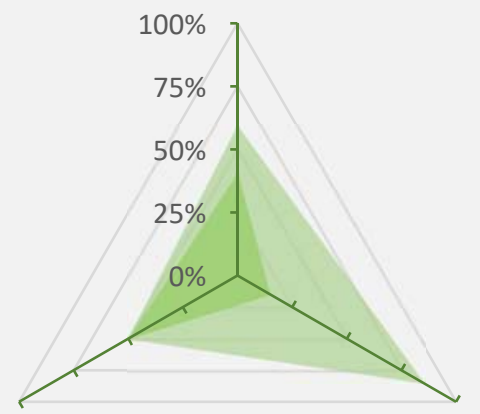

18- A reputação, ou seja, a opinião dos consumidores sobre o produto, está associada à imagem que as pessoas têm do lugar ou território de produção.
17- A reputação, ou seja, a opinião dos consumidores sobre o produto, está associada à sua qualidade como produto típico (autêntico e/ou singular).

Pouco Significativo Muito Significativo

Fonte: Elaborada pelos autores a partir dos dados da pesquisa (2019).

O grau de reputação refere-se à opinião dos consumidores sobre o produto específico de uma IG. Essa variável é representada na Figura 5. Na percepção dos respondentes (85\%), a reputação do produto da IG em análise é reconhecida pela sua tipicidade, ou seja, por ser um produto diferencial em relação aos demais. Já acerca do reconhecimento pela sua excelência alimentar ou pela imagem que as pessoas têm do lugar de produção, a significância fica restrita a menos de 50\%. Ou seja, ao mesmo tempo que o fator tipicidade territorial do produto pode servir como fator propulsor na divulgação, torna-se necessário ressaltar, em especial, a relação entre produto específico e local de produção.

A Figura 6 traz os resultados da pesquisa sobre a capacidade dos atores envolvidos na experiência para estabelecer relações de cooperação e integração. A percepção manifestada pelos respondentes não é nada positiva, em especial no que se refere a relações de cooperação e integração, tanto entre atores do mesmo elo como entre os diferentes elos da cadeia produtiva. Isso significa que há um deficit de inter-relacionamento, o que não é positivo. A situação é um pouco melhor no que se refere às relações com organizações de apoio. Outra questão muito problemática é o fato de que os respondentes se manifestaram no sentido de que há uma baixa homogeneidade entre as empresas do setor produtivo analisado, o que caracteriza concentração econômica e distribuição desigual do poder de decisão, fator este negativo, em se tratando da necessidade de o setor estar coeso na obtenção de objetivos que são comuns, fator indispensável para o sucesso da organização territorial da IG. 
Figura 6 - Capacidade dos atores de estabelecer relações de cooperação e integração 19- Capacidade dos atores locais de estabelecer relações
de cooperação e integração entre os atores do mesmo elo
da cadeia produtiva (no setor produtivo e no setor
industrial).

22- Grau de homogeneidade do setor empresarial envolvido no processo de produção do produto com especificidade territorial, no que se refere à dimensão econômica ou operacional (se existe de concentração da produção ou de influência nas decisões do setor, é pouco homogêneo).

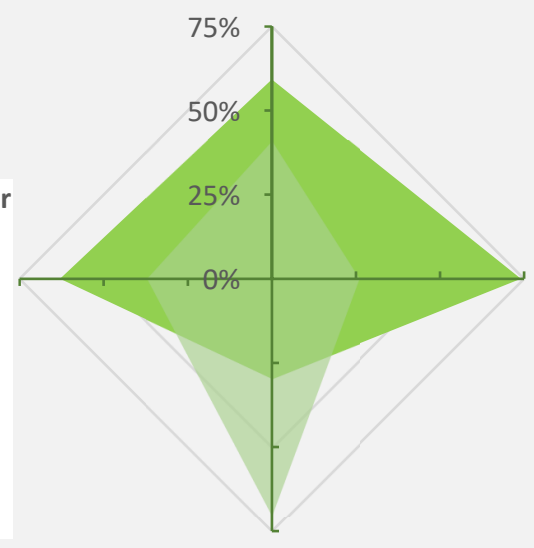

20- Capacidade dos atores locais de estabelecer relações de cooperação e integração entre os atores dos diferentes elos da cadeia produtiva (setor produtivo, industrial, mercado varejista, consumidor).

21- Capacidade dos atores locais de estabelecer relações de cooperação e integração com as organizações de apoio, como universidades, centros de pesquisa e/ou órgãos governamentais de pesquisa e extensão ou consultorias.

- Pouco Significativo Muito Significativo

Fonte: Elaborada pelos autores a partir dos dados da pesquisa (2019).

Por fim, na Figura 7, é apresentado o resultado da pesquisa no que se refere à capacidade de iniciativa dos atores que fazem parte da cadeia produtiva do produto com IG, na forma de ações coletivas que resultem em benefícios para todos. Das variáveis estudadas, a menos problemática é a que se refere à busca de apoio institucional (78\%). Acerca das demais ações, em vista da valorização dos recursos territoriais (questão ambiental, por exemplo), do compartilhamento de conhecimentos técnicos ou produtivos e com o objetivo de ampliar a variedade de produtos oferecidos ao mercado, os respondentes afirmaram que elas têm menor significância. Isso significa que o setor tem muito a avançar em termos de ações de cooperação e integração. Em relação à questão ambiental, é preocupante a situação apresentada, de pouca valorização, pois o produto de IG aqui analisado depende muito de ações de preservação ambiental.

Estas são as principais análises que podem ser feitas, considerando a percepção dos atores entrevistados. 
Figura 7 - Ações coletivas que resultem em benefícios para todos os elos da cadeia produtiva

23- Capacidade de iniciativa dos atores locais para avançar na busca coletiva de objetivos comuns, que venham em benefício do setor, no que se refere à valorização dos recursos territoriais (preservação ambiental).
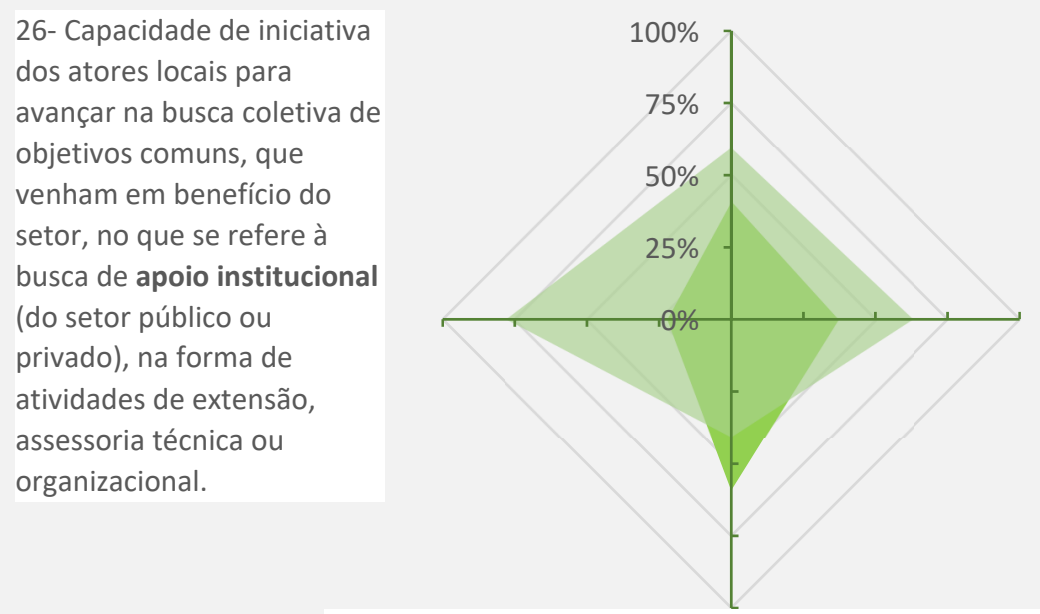

24- Capacidade de iniciativa dos atores locais para avançar na busca coletiva de objetivos comuns, que venham em benefício do setor, no que se refere ao compartilhamento de conhecimentos técnicos ou produtivos.

25- Capacidade de iniciativa dos atores locais, para avançar na busca coletiva de objetivos comuns, que venham em benefício do setor, de modo a articular-se para ampliar a variedade de produtos oferecidos ao mercado.

Fonte: Elaborada pelos autores a partir dos dados da pesquisa (2019).

\section{CONSIDERAÇÕES FINAIS}

O propósito central do estudo do qual resultou este texto foi apresentar e fazer uma testagem-piloto de um instrumento de pesquisa que atendesse ao objetivo de investigar as dimensões e os parâmetros para a prospecção e/ou avaliação de experiências de associativismo territorial, com o caso das que se constituem em signos distintivos territoriais. Como se tinha como objetivo, também, testar a validade do instrumento de pesquisa, propositalmente, sua aplicação foi feita em duas realidades sobre as quais os autores do texto tinham um bom conhecimento. Assim, pelos resultados apresentados, pode-se afirmar que a proposta metodológica, com o instrumento utilizado, apresenta as condições necessárias para buscar as respostas pretendidas. Ou seja, é possível recomendar a sua aplicação em outras experiências similares.

As quatro dimensões abrangidas pela proposta metodológica aqui testada - (i) reconhecimento de signos distintivos territoriais; (ii) vínculo territorial da produção; (iii) reconhecimento da notoriedade ou reputação do produto específico; (iv) avaliação da dinâmica territorial do setor produtivo envolvido na experiência de IG -, as quais atendem às recomendações dos autores referenciados, remetem-se aos fatores socioeconômicos, culturais e organizacionais do território de abrangência de experiências de signos distintivos territoriais, que se tornam indispensáveis de se considerar no processo de organização, ativação e acompanhamento de tais experiências de associativismo territorial. Assim, com base na análise de experiências de IG, como as relatadas nas publicações mencionadas, é possível afirmar que o insucesso da quase maioria delas deve-se à excessiva preocupação com as questões de ordem legal e pouca atenção aos processos socioeconômicos e histórico-culturais que fazem parte da dinâmica territorial. 
Por fim, fazendo referência em específico às análises permitidas pelo resultado da investigação, em relação à experiência em estudo, poderiam ser destacados fatores positivos e outros nem tanto. Entre os fatores positivos, constata-se: (i) a efetividade no reconhecimento da imagem que representa o signo distintivo territorial; (ii) o forte enraizamento territorial da atividade produtiva; (iii) o reconhecimento e a notoriedade do produto de IG, que são formados pelas suas características específicas, o que é fundamental, em se tratando de uma IG do tipo Denominação de Origem; (iv) o reconhecimento da importância no que se refere à busca de apoio institucional.

Entre os aspectos negativos e que indicam necessidades de avanços na experiência, destacam-se: (i) baixo reconhecimento e notoriedade quanto à especificidade do produto de IG, tanto nacional como internacionalmente, indicando a necessidade de ações de divulgação; (ii) baixa capacidade dos atores envolvidos na experiência para estabelecer relações de cooperação e integração entre os atores do mesmo elo e entre os diferentes elos da cadeia produtiva; (iii) a percepção sobre a baixa homogeneidade entre as empresas do setor produtivo analisado, o que caracteriza concentração econômica e distribuição desigual do poder de decisão; (iv) percepção sobre a baixa valorização dos recursos territoriais (questão ambiental, por exemplo) e dificuldades no compartilhamento de conhecimentos técnicos ou produtivos e com o objetivo de ampliar a variedade de produtos oferecidos ao mercado, entre os atores envolvidos na experiência.

As evidências permitidas pela pesquisa em relação aos fatores positivos ou negativos, acima referidos, são elementos da maior importância, pois permitirão indicar aos atores envolvidos na experiência as ações necessárias, tanto para realçar os impactos positivos como para superar as dificuldades ainda presentes. Estudos futuros, com diferentes instrumentos ou procedimentos metodológicos, poderão apontar outros elementos para análise da experiência e prospecção dos avanços necessários.

\section{REFERÊNCIAS}

ARANDA CAMACHO, Y. V. Productos agroalimentarios e identidade del território: un modelo de decisión para orientar la seleción de selos de origen. 2015. 325p. Tese (Doutorado em Desenvolvimento Rural) - Departamento de Economía, Sociología y Política Agrarias, Universidad de Córdoba, Espanha, 2015.

BRUCH, K. L. B. Signos distintivos de origem: entre o velho e o novo mundo vitivinícola. 2011. Tese (Doutorado em Direito) - Universidade Federal do Rio Grande do Sul; Université Rennes I, Porto Alegre, RS; Rennes, France, 2011.

CHAMPREDONDE, M. La valorización de la tipicidad cultural y territorial de productos mediante certificaciones en países de América Latina. In: FROEHLICH, J. M. (Org.). Desenvolvimento territorial: produção, identidade e consumo. Ijuí (RS): Editora UNIJUÍ, 2012. p. 119-65.

CHAMPREDONDE, M.; CASIOROVSKI, J. G. Agregado de valor o valorización? Reflexiones a partir de denominaciones de origen en América Latina. RIVAR, Santiago do Chile, v. 3, n. 9, p. 147-72, set. 2016.

COVAS, A. A. Os territórios digitais: o decálogo da smartificação. Jornal Público, Lisboa, Portugal, 17 de fevereiro de 2018. Disponível em: https://www.publico.pt/2018/02/17/sociedade/opiniao/os-territoriosdigitais-o-decalogo-da-smartificacao-1803261. Acesso em: 14 maio 2018.

DALLABRIDA, V. R. Valorização do território, signos distintivos e desenvolvimento territorial: uma aproximação teórica e indicativos metodológicos. In: ENANPUR, 18., Natal, 27-31 maio 2019. Anais [...], Natal, 2019a. Disponível em: http://anpur.org.br/xviiienanpur/anaisadmin/capapdf.php?reqid=23. Acesso em: 16 jan. 2020. 
DALLABRIDA, V. R. "Significar territórios" para reafirmar sua especificidade e identidade territorial: aproximações teóricas e indicativos metodológicos. In: SEMINÁRIO INTERNACIONAL SOBRE DESENVOLVIMENTO REGIONAL, 9., Santa Cruz do Sul, RS, 11-13 set. 2019. Anais [...]. Santa Cruz do Sul, RS: Unisc, 2019b. Disponível em: https://online.unisc.br/acadnet/anais/index.php/sidr/article/view/18987. Acesso em: 16 jan. 2020.

DALLABRIDA, V. R. Teorias do desenvo/vimento: aproximações teóricas que tentam explicar as possibilidades e desafios quanto ao desenvolvimento de lugares, regiões, territórios ou países. Curitiba, PR: CRV, 2017.

DALLABRIDA, V. R. Território, governança e desenvolvimento territorial: indicativos teórico-metodológicos, tendo a Indicação Geográfica como referência. São Paulo: LiberArs, 2016a.

DALLABRIDA, V. R. Ativos territoriais, estratégias de desenvolvimento e governança territorial: uma análise comparada de experiências brasileiras e portuguesas. Revista EURE, Santiago do Chile, v. 42, n. 126, p. 187-212, mayo 2016b.

DALLABRIDA, V. R. (Org.). Indicação geográfica e desenvolvimento territorial: reflexões sobre o tema e potencialidades no Estado de Santa Catarina. São Paulo: LiberArs, 2015.

DALLABRIDA, V. R. (Org.). Desenvolvimento territorial: políticas públicas brasileiras, experiências internacionais e a Indicação Geográfica como referência. São Paulo: LiberArs, 2014.

DALLABRIDA, V. R. (Org.). Território, identidade territorial e desenvolvimento regional: reflexões sobre Indicação Geográfica e novas possibilidades de desenvolvimento com base em ativos com especificidade territorial. 1. ed. São Paulo: LiberArs, 2013.

DALLABRIDA, V. R. A gestão territorial através do diálogo e da participação. Scripta Nova, Barcelona, Espanha, v. XI, n. 245 (20), ago. 2007.

DALLABRIDA, V. R.; TOMPOROSKI, A. A.; PLAZA, J. J. T.; RUÍZ, A. R. P. Activando el patrimonio territorial como estrategia de desarrollo de regiones estancadas: el caso del Territorio del Contestado. Informe Gepec, Toledo, PR, v. 23, Edição Especial, p. 91-114, 2019.

DALLABRIDA, V. R.; COVAS, M. M. C. M.; COVAS, A. M. A. Inovação, desenvolvimento e espaço urbano: uma relação necessária, mas não suficiente. RBEUR - Revista Brasileira de Estudos Urbanos e Regionais, Recife, PE, v. 19, n. 2, p. 360-78, maio/ago. 2017.

GARRIDO, M. D.; RAMOS, E. Calidad y desarrollo rural: una propuesta metodológica para la evaluación de marcas de calidad territorial. Revista Española de Estudios Agrosociales y Pesqueros, n. 234, p. 127-57, 2013.

HAESBAERT, R. O mito da desterritorialização: do "fim dos territórios" à multiterritorialidade. 6. ed. Rio de Janeiro: Bertrand Brasil, 2011.

MARTínEZ-VILLALBA, J. C. R. Teoría general de los signos distintivos. Revista la Propriedad Inmaterial, n. 18, p. 191-219, nov. 2014.

MASCARENHAS, G.; WILKINSON, J. Indicações geográficas em países em desenvolvimento: Potencialidades e desafios. Revista de Política Agrícola, Brasília, DF, ano XXIII, n. 2, p. 103-15, abr./maio/jun. 2014.

NIEDERLE, P. A. (Org.). Indicações geográficas: qualidade e origem nos mercados alimentares. 1. ed. Porto Alegre: UFRGS, 2013. v. 1.

PAVÓN, P.; GÓMEZ MUNHÓZ, A. C. Pautas de implantación de signos de calidad territorial en Andalicía. 
In: MORENO, L.; SANCHEZ, M.; SIMÕES, O. (Coord.). Cultura, inovação e território: o agroalimentar e o rural. Lisboa: Sociedade Portuguesa de Estudos Rurais, 2009. p. 75-85.

PECQUEUR, B. A guinada territorial da economia global. Política \& Sociedade, Florianópolis, SC, n. 14, p. 79-105, abr. 2009.

SAKR, M. R.; DALLABRIDA, V. R. Produtos de Santa Catarina com identidade territorial. Política Agrícola, Brasília, ano XXIV, n. 3, p. 102-13, jul./ago./set. 2015.

SAQUET, M. Por uma geografia das territorialidades e das temporalidades. Uma concepção multidimensional voltada para a cooperação e para o desenvolvimento territorial. 2. ed. ver. e ampl. Rio de Janeiro: Ed. Consequência, 2015.

VANDECANDELAERE, E.; ARFINI, F.; BELLETTI, G.; MARESCOTTI, A. (Ed.). Uniendo personas, territorios y productos. Guía para fomentar la calidad vinculada al origen y las indicaciones geográficas sostenibles. Roma: FAO/SINER-GI, 2011. (reimpressão).

\section{Sobre os autores:}

Valdir Roque Dallabrida: Geógrafo. Doutor em Desenvolvimento Regional, com atuação no Programa de Mestrado em Desenvolvimento Regional da Universidade do Contestado, SC, Brasil. E-mail: valdirdallabrida@gmail.com, Orcid: http://orcid.org/0000-0003-2927-960X

Kelly Samantha Baukart: Graduanda em Administração e bolsista de Iniciação Científica na Universidade do Contestado, SC, Brasil. E-mail: kellybaukart@gmail.com, Orcid: http://orcid.org/0000-0002-2749-2047

Walison Guinzani: Graduando em Engenharia Elétrica e bolsista de Iniciação Científica na Universidade do Contestado, SC, Brasil. E-mail: w.guinzani@gmail.com, Orcid: http://orcid.org/0000-0003-4186-0894 
